\title{
Lacunes in Raamplan 1994: aanvullende eindtermen rond chronisch zieken
}

\author{
J. Pols, J. van der Griend
}

\section{Samenvatting}

Inleiding: De aanduiding 'chronische aandoening' heeft voor patiënt en arts implicaties op somatisch, psychosociaal en maatschappelijk gebied. In de opleiding geneeskunde wordt tot op heden weinig systematisch aandacht aan dit gegeven geschonken. Analyse van Raamplan 1994 laat zien dat ook de gezamenlijke eindtermen van de faculteiten geneeskunde lacunes op dit gebied lijken te vertonen. In Groningen is door middel van een consensusprocedure onderzocht of en welke aanvullingen op Raamplan 1994 gewenst zijn.

Methode: Na consultatie van medici, patiënten en andere deskundigen op het gebied van chronisch zieken zijn voor de gesignaleerde lacunes voorstellen voor aanvullende eindtermen geformuleerd. Door middel van een Delphi-procedure met dertig deelnemers is vastgesteld of de voorgestelde aanvullende eindtermen voor iedere arts die in Groningen afstudeert, vereist, wenselijk, niet echt nodig of onnodig zijn. Van consensus is gesproken als minimaal twee derde van de respondenten dezelfde eis stelde.

Resultaten: Het bleek mogelijk om met deze procedure 84 'algemene eindtermen' en 39 'problemen' aan het Raamplan toe te voegen.

Discussie: De resultaten bevestigen de geconstateerde lacunes. De aanvullende eindtermen bieden uitstekende gebruiksmogelijkheden bij evaluatie en ontwikkeling van onderwijs, ook in andere curricula, en voor de discussie over de herziening van Raamplan 1994. (Pols J, Griend J van der. Lacunes in Raamplan 1994: aanvullende eindtermen rond chronisch zieken. Tijdschrift voor Medisch Onderwijs 2001;20(3): 91-99.)

\section{Inleiding}

Vooral bij patiënten met een chronische aandoening moet een arts niet alleen adequaat handelen op medisch-biologisch terrein, maar ook aandacht hebben voor psychosociale en maatschappelijke gevolgen voor de patiënt. Het gebrekkig signaleren van problemen op die laatste gebieden wordt door patiënten op dit moment echter gezien als een belangrijk knelpunt in de zorgverlening door (medische) hulpverleners. ${ }^{1}$ Nederland kent veel mensen met een chronische aandoening en tot 2015 wordt voor de meest frequent voorkomende aandoeningen een forse stijging van het aantal patiënten verwacht. ${ }^{2}$ Mede daarom probeert de overheid te stimuleren dat psychosociale zorg integraal onderdeel uitmaakt van de reguliere zorg voor mensen met een chronische aandoening. ${ }^{3}$

Vanwege de geschetste ontwikkelingen heeft de Faculteit der Medische Wetenschappen in Groningen de wijze waarop zij haar studenten voorbereidt op contacten met chronisch zieken nader bekeken. Dat gebeurde binnen het project 'Onderwijs rond chronisch zieken in Curriculum 2000' (verder project chronisch zieken genoemd). ${ }^{4}$ Binnen het project is een inventarisatie gemaakt van het bestaande onderwijs aan de Nederlandse faculteiten geneeskunde rond chronisch zieken en de gevolgen van chronische aandoeningen op psychosociaal en maatschappelijk terrein. ${ }^{5}$ Deze inventarisatie liet zien dat in de Nederlandse curricula het onderwijs sterk 
biomedisch en kennisgeoriënteerd is. Psychosociale en maatschappelijke aspecten komen beperkt aan bod en er vindt geen systematische vertaling plaats naar het vaardigheidsonderwijs en de co-assistentschappen. Deze bevinding riep de vraag op of er voor de psychosociale en maatschappelijke aspecten van chronische ziekte adequate eindtermen zijn geformuleerd.

Eindtermen vormen het uitgangspunt voor het onderwijs en ze bakenen voor het curriculum een referentiekader af. 6 Voor de acht Nederlandse faculteiten geneeskunde bevat Raamplan 1994 de gemeenschappelijke eindtermen. ${ }^{7}$ In 1997 hebben de algemene eindtermen en de probleemlijst uit Raamplan 1994 een wettelijke basis gekregen toen ze in een algemene maatregel van bestuur - het Besluit opleidingseisen arts - werden toegevoegd aan de Wet op de beroepen in de individuele gezondheidszorg (Wet BIG). ${ }^{8}$ Daarmee is formeel juridisch vastgelegd aan welke eisen elke student geneeskunde minimaal moet voldoen na zes jaar studie, ongeacht aan welke faculteit hij afstudeert. Voor het beantwoorden van de vraag of er voor de psychosociale en maatschappelijke aspecten van chronische ziekte adequate eindtermen zijn geformuleerd, is het dus noodzakelijk om naar Raamplan 1994 te kijken.

De leden van de projectgroep chronisch zieken (twee medisch specialisten, twee onderwijskundigen, een psycholoog en een student) hebben de wettelijke kern van het Raamplan beoordeeld. Zij waren van mening dat in de algemene eindtermen te weinig aandacht wordt besteed aan de specifieke aspecten van het werk van de arts in contact met chronisch zieken. Een concreet voorbeeld daarvan is dat de eisen ten aanzien van het medisch probleemoplossen zich beperken tot consulten die betrekking hebben op de diagnostiek van een aandoening. Het probleemoplossen tijdens vervolgconsulten consulten waarin de diagnose (al langer) bekend is, wat geldt voor het leeuwendeel van de consulten van patiënten met een chronische aandoening - wordt niet als apart onderwerp behandeld. Bij de beoordeling van de probleemlijst bleek dat van de 353 problemen die deze lijst bevat, er slechts tien à twintig (circa 5\%) direct of indirect betrekking hebben op chronisch zieken. De overige problemen betreffen acute aandoeningen of acute episodes in het verloop van een chronische aandoening.

$\mathrm{Na}$ deze interne beoordeling was de vraag of de geconstateerde lacunes bevestigd zouden worden, als een panel van deskundigen gevraagd werd te oordelen over aanvullende eindtermen op het gebied van chronisch zieken.

\section{Methode}

Voor de lacunes in de algemene eindtermen en de probleemlijst van Raamplan 1994 zijn voorstellen voor amendementen geformuleerd. In een consensusprocedure is door een panel van deskundigen vastgesteld of deze amendementen aan Raamplan 1994 moesten worden toegevoegd.

De amendementen bestonden uit voorstellen voor zowel nieuw toe te voegen eindtermen als precisering van bestaande eindtermen. Ze zijn gebaseerd op de volgende bronnen:

- Suggesties voor kernpunten voor het onderwijs zoals gedaan door de Commissie van Advies bij het project 'Onderwijs rond chronisch zieken in C2000';

- Kerndoelstellingen tot het doctoraal geneeskunde van de Faculteit der Medische Wetenschappen in Nijmegen; 9

- Doelstellingen uit het deskundigheidsbevorderingspakket: Chronisch zieken, uw zorg? 10 
- Doelstellingen geriatrie van de Nederlandse Vereniging voor Geriatrie; 11

- Interviews afgenomen in het kader van het project 'Onderwijs rond chronisch zieken in C2000';

- Suggesties voor aanvulling van Raamplan 1994 die gedaan zijn door de koepelorganisatie van patiëntenverenigingen van patiënten met chronische aandoeningen (het Werkverband Organisaties Chronisch Zieken);

- Artikelen over onderwijs rond chronisch zieken.

De voorstellen zijn door een projectmedewerker opgesteld, de projectgroep chronisch zieken heeft besloten welke daarvan in de consensusprocedure zouden worden ingebracht. Alle deelnemers aan de consensusprocedure hebben in de loop ervan de gelegenheid gekregen om nieuwe voorstellen voor amendementen te leveren.

Voor de consensusprocedure (voor meer informatie zie bijlage 1) is een variant op de Delphi-procedure gebruikt, een werkwijze die vaker wordt gebruikt om tot eindtermen te komen. ${ }^{12-14}$ Naar aanleiding van eerdere ervaringen is een gemodificeerde Delphi-procedure gebruikt met twee schriftelijke rondes en een plenaire vergadering. ${ }^{14}$

De keuze voor de initiële schriftelijke rondes werd bepaald door de wens om een groep deelnemers met grote verschillen qua achtergrond (medici, verpleegkundigen, paramedici en patiënten) de gelegenheid te geven om een gelijkwaardige inbreng te hebben. De afsluitende bijeenkomst is georganiseerd om het aantal schriftelijke rondes te beperken. De hele procedure besloeg een periode van vijf weken.

Aan de consensusprocedure namen de dertig personen deel die actief bij het project chronisch zieken waren betrokken: zes leden van de projectgroep chronisch zieken (zij hadden nog geen individueel waardeoordeel over de voorstellen uitgesproken; de projectmedewerker die de procedure voorbereidde en uitvoerde, deed niet mee) en 24 leden van de Commissie van Advies bij het project chronisch zieken. De groep bestond uit vijftien medici (twaalf medisch specialisten, een huisarts en twee sociaal geneeskundigen), zes patiënten of hun vertegenwoordigers, vier onderwijskundigen, twee psychologen, een verpleegkundige, een maatschappelijk werkster en een student.

In elke ronde konden de deelnemers hun oordeel over de amendementen uitspreken op een vierpunts Likertschaal. Daarbij moest men de vraag beantwoorden of men deze eindterm voor iedere arts die in Groningen afstudeert, vereist, wenselijk, niet echt nodig of onnodig vond. Onder vereist werd daarbij verstaan: "Elke arts die in Groningen afstudeert, moet altijd aan deze eindterm voldoen; de faculteit is dus verplicht om hierover onderwijs aan te bieden en studenten hierover te toetsen". Onder wenselijk: "Niet elke arts die in Groningen afstudeert, hoeft altijd aan deze eindterm te voldoen, maar indien er ruimte in het curriculum zit, is het wenselijk dat de faculteit over dit onderwerp onderwijs aanbiedt". De deelnemers konden daarnaast suggesties voor aanpassingen van amendementen en nieuwe aanvullingen doen. Van consensus is gesproken als minimaal twee derde van de respondenten dezelfde eis stelde.

In de eerste schriftelijke ronde zijn alle amendementen ter beoordeling voorgelegd. In de tweede ronde is bij alle amendementen waarover na de eerste ronde consensus bestond, het vereiste niveau aangegeven. Bij amendementen waarover nog geen consensus bestond, werd voor elk niveau aangegeven hoeveel respondenten daarvoor gekozen hadden. 
Suggesties voor nieuwe eindtermen of tekstuele aanpassingen zijn in de tweede ronde verwerkt. Om de deelnemers de mogelijkheid te geven de eigen mening met die van de groep als geheel te vergelijken, kregen zij hun materiaal uit de eerste ronde terug. Voor de plenaire derde ronde is het schriftelijk materiaal op dezelfde wijze bewerkt als na de eerste ronde, met dien verstande dat nu bij elk amendement waarover na de tweede ronde nog geen consensus bereikt was, door de projectgroep chronisch zieken een voorstel werd gedaan voor het vereiste niveau. Deze eindtermen zijn besproken en - eventueel na aanpassing van het niveau - vastgesteld. In deze laatste ronde kreeg elke deelnemer inzage in zijn of haar ingevulde enquête uit de tweede ronde.

\section{Resultaten}

De respons bedroeg in beide schriftelijke rondes $90 \%$. Alle deelnemers hebben in deze rondes minimaal eenmaal hun oordeel uitgesproken. Bij de derde ronde was
$67 \%$ van de deelnemers aanwezig. Het aantal respondenten varieerde per vraag, waardoor het aantal respondenten met dezelfde mening, dat nodig was om consensus te bereiken, in de praktijk varieerde van vijftien tot zeventien.

In totaal zijn 161 amendementen beoordeeld: 118 bij de algemene eindtermen (ronde 1 start met 99, 19 toevoegingen in ronde 1 en 2) en 43 bij de problemen (ronde 1 start met 43, geen toevoegingen). In de loop van de rondes werd besloten om 38 amendementen (34 algemene eindtermen en 4 problemen) te laten vervallen, omdat er sprake was van overlappingen met andere eindtermen en een aantal kon worden samengevoegd. Er werden op aanraden van de deelnemers 19 nieuwe amendementen toegevoegd. Het verloop van de consensusprocedure wordt in tabel 1 weergegeven.

Uiteindelijk zijn 84 algemene eindtermen en 39 problemen aan het Raamplan toegevoegd. Tabel 1 laat zien dat er na de tweede schriftelijke ronde over meer dan de helft

Tabel 1. Verloop consensusprocedure.

\begin{tabular}{|c|c|c|c|c|c|}
\hline & $\begin{array}{l}\text { te } \\
\text { beoordelen }\end{array}$ & vervallen & toegevoegd & $\begin{array}{l}\text { consensus } \\
\text { per ronde } \\
N(\%)^{*}\end{array}$ & $\begin{array}{l}\text { cumulatieve } \\
\text { consensus } \\
N(\%)^{* *}\end{array}$ \\
\hline \multicolumn{6}{|l|}{ ronde 1} \\
\hline eindtermen & 99 & 22 & 12 & $26(26.3)$ & $26(31.0)$ \\
\hline $\begin{array}{l}\text { problemen } \\
\text { ronde } 2\end{array}$ & 43 & 1 & 0 & $4 \quad(9.3)$ & $4 \quad(10.3)$ \\
\hline eindtermen & 63 & 8 & 7 & $23(36.5)$ & $49(58.3)$ \\
\hline $\begin{array}{l}\text { problemen } \\
\text { ronde } 3\end{array}$ & 38 & 1 & 0 & $18(47.4)$ & $22(56.4)$ \\
\hline eindtermen & 39 & 4 & 0 & 35 (89.7) & $84(100)$ \\
\hline problemen & 19 & 2 & 0 & $17(89.5)$ & 39 (100) \\
\hline
\end{tabular}

$\mathrm{N}=$ aantallen eindtermen/problemen

$\%=$ percentage te beoordelen items waarover consensus ontstaat

* = aantal en percentage per rij; ${ }^{* *}$ eindtotaal kolom $=100 \%$ 
Tabel 2. Resultaten consensusprocedure.

\begin{tabular}{lcccc}
\hline & $\begin{array}{c}\text { algemene eindtermen } \\
(\mathrm{N}=84)\end{array}$ & $\begin{array}{c}\text { problemen } \\
(\mathrm{N}=39)\end{array}$ \\
\hline & nieuw & precisering & nieuw & precisering \\
vereist & 48 & 16 & 23 & 5 \\
wenselijk & 20 & - & 11 & - \\
\hline
\end{tabular}

van de amendementen consensus bestond en dat er na de derde ronde over alle amendementen consensus was bereikt.

Geen enkel amendement werd beoordeeld als niet echt nodig of onnodig. Consensus betekende steeds dat het amendement betrekking had op een eindterm die vereist dan wel wenselijk werd gevonden. Tabel 2 laat zien wat het gewenste niveau is voor de toegevoegde algemene eindtermen en problemen en ook of het daarbij gaat om nieuw toegevoegde eindtermen dan wel om preciseringen van bestaande eindtermen.

De meerderheid van de toevoegingen en preciseringen heeft te maken met het verbreden van het voornamelijk medisch-biologische aandachtsgebied van Raamplan 1994 naar het terrein van de psychische en sociale aspecten van het leven met een chronische aandoening. Voorbeelden hiervan zijn:

- systematisch anamnestische gegevens kunnen verzamelen m.b.t. de aandoening en de gevolgen ervan op lichamelijk, psychisch en sociaal gebied (nieuw/ vereist)

- beschouwen van de klachten in perspectief van de zich ontwikkelende ziektel adaptatie aan de ziekte (nieuw/vereist)

Een deel heeft te maken met de benadering van de patiënt als mondig en autonoom individu, waarbij rekening wordt gehouden met diens gevoelens, wensen, belasting en draagvermogen. Voorbeelden hiervan zijn:

- bepalen van het therapeutisch doel, in overleg met de patiënt, gericht op het verbeteren van de kwaliteit van het leven, zowel op korte als ook op lange termijn (precisering/vereist)

Het therapeutisch gesprek en het adviseren/voorlichten zijn belangrijke elementen in het professionele contact met chronisch zieken. Aan dit deel van het Raamplan is een flink aantal eindtermen toegevoegd. Met name ten aanzien van het begeleiden van chronisch en ongeneeslijk zieken, partner, vrienden en familie zijn van bestaande eindtermen de eisen verscherpt. Zo is de eis: 'In zijn opleiding kennis gemaakt hebben met ...' uitgebreid met: 'en inzicht verworven hebben in ...'. Ten slotte zijn er aanvullingen gekomen ten aanzien van de benodigde 'persoonlijke aspecten'. Deze hebben alle te maken met de arts-patiëntrelatie. Bijvoorbeeld:

- streeft naar een zo gelijkwaardig mogelijke arts-patiëntrelatie, waarbij de patiënt als ervaringsdeskundige geaccepteerd wordt en de arts eerlijke informatie geeft (precisering/vereist)

- kan emotionele reacties van de patiënt plaatsen in het kader van coping met de ziekte (nieuw/vereist)

- heeft inzicht in het fenomeen van positieve en negatieve overdracht van een patiënt ten opzichte van een arts en vice versa en kan op basis van dat inzicht handelen (nieuw/vereist)

In de probleemlijst is bij de chronische ziektes het woord: chronisch toegevoegd, zodat deze groep duidelijker herkenbaar wordt. Het merendeel van de toegevoegde 
problemen heeft betrekking op ziekteoverstijgende aspecten van de omgang met chronisch(e) ziek(t)en. Bijvoorbeeld:

- adaptatie aan/leven met een chronische aandoening (nieuw/vereist)

- functieverlies (nieuw/vereist)

- ziektebeleving/-perceptie (nieuw/vereist)

\section{Discussie}

De tekortkomingen die door de projectgroep chronisch zieken werden geconstateerd in de algemene eindtermen en in de probleemlijst van Raamplan 1994 zijn door een panel van deskundigen bevestigd: geen enkel voorgesteld amendement werd als 'niet zo nodig' of 'onnodig' beoordeeld. De gekozen werkwijze heeft erin geresulteerd dat de gesignaleerde lacunes zijn aangevuld met nieuwe eindtermen en preciseringen van bestaande eindtermen. De aanvullingen liggen grotendeels op het gebied van psychosociale en maatschappelijke aspecten van chronisch ziek zijn en de rol van de arts daarbij.

In totaal zijn 123 grotere en kleinere amendementen aan de wettelijke kern van Raamplan 1994 toegevoegd. Daarvoor is een beroep gedaan op een groep deskundigen die werd aangesproken op haar kennis van chronisch zieken. Voor zover wij hebben kunnen nagaan, is het voor het eerst dat een dergelijke disciplineoverstijgende benadering gekozen is. Op het gebied van eindtermen rond chronisch zieken zijn er weliswaar twee eerdere initiatieven geweest, maar beide keren betrof het een discipline (geriatrie en reumatologie) die haar visie gaf op de eindtermen voor de basisopleiding. 1115 Onze werkwijze ligt meer in het verlengde van die van Raamplan 1994, waarbij een groot panel van artsen met diverse achtergronden de relevantie van de voorgestelde eindtermen beoordeeld heeft. ${ }^{7}$ Zowel bij het tot stand komen van Raamplan 1994 als bij de aanvullende eindtermen rond chronisch zieken is daarmee een zekere garantie gegeven dat het daadwerkelijk om algemene eindtermen gaat, wat wil zeggen dat het voldoen aan deze eisen voor elke afstuderende arts relevant is. Mede daardoor vormen de aanvullende eindtermen rond chronisch zieken een vruchtbare basis om curricula aan te toetsen en om onderwijs op te baseren. Vanuit dat oogpunt gezien zijn ze niet alleen van nut voor de Faculteit der Medische Wetenschappen in Groningen, maar kunnen ze ook landelijk gebruikt worden. Daartoe zijn ze inmiddels ingebracht ten behoeve van de discussie over de herziening van Raamplan 1994.

Met de gebruikte Delphi-procedure bleek het mogelijk te zijn om in korte tijd over een groot aantal amendementen op Raamplan 1994 consensus te bereiken. De respons was hoog in de eerste twee rondes; in de derde ronde waren juist voldoende deelnemers aanwezig om het van tevoren vastgestelde consensusniveau te kunnen bereiken. Deelname aan een schriftelijke procedure is blijkbaar makkelijker te realiseren, mogelijk omdat men zijn betrokkenheid op een zelfgekozen moment kan laten blijken. Omdat na de tweede schriftelijke ronde het percentage consensus fors steeg, lijkt het de moeite waard om bij toekomstig gebruik het aantal schriftelijke rondes uit te breiden en eventueel de plenaire bijeenkomst te laten vervallen.

De vraag blijft natuurlijk of de aanvullende eindtermen het uiteindelijke doel van het project 'Onderwijs rond chronisch zieken in C2000' dichterbij brengen. Dat doel is: "het ontwikkelen van een onderwijsprogramma dat de zekerheid verschaft dat iedere arts die in Groningen wordt opgeleid zowel wat kennis als wat vaardigheden en attitudes betreft een 
stevige basis heeft op het gebied van chronisch(e) ziek(t)en". ${ }^{4}$ Met het formuleren van aanvullende eindtermen is in elk geval de inhoud van de 'stevige basis' concreet onder woorden gebracht. Voor alle betrokkenen is daarmee zichtbaar gemaakt waaraan in het onderwijs aandacht moet worden besteed om het gewenste doel te bereiken.

Het project 'Onderwijs rond chronisch zieken in C2000' is mede mogelijk gemaakt door een subsidie van ZorgOnderzoek Nederland (projectnummer 9807021). Nadere informatie over het project en de resultaten ervan zijn te vinden op de website http://coo.med.rug.nl/fmw/pcz.htm. Via deze site is ook de volledige tekst van de aanvullende eindtermen verkrijgbaar.

\section{Literatuur}

1. Directie Voorlichting en Communicatie. Factsheet chronisch ziekenbeleid (FS 06-N-1997). Rijswijk: Ministerie van Volksgezondheid, Welzijn en Sport; 1997.

2. Ruwaard D, Kramers PGN, redactie. Volksgezondheid Toekomst Verkenning 1997. De som der delen. Maarssen: Elsevier/De Tijdstroom; 1997.

3. Chronisch Zieken aan zet; tussenbalans chronisch ziekenbeleid 1991-1994. Zoetermeer: Nationale Commissie Chronisch Zieken; 1994.

4. Pols J, Rijswijk MH van, Zwierstra RP, Meininger AK, Aukes LC, Albada BL van, et al. Project 'onderwijs rond chronisch zieken in C2000'. In: Spaai GWG, Verweij AMJJ, Remmen R, Dolmans DHJM, Denekens JPM, Smal JA, et al., redactie. Gezond Onderwijs 8. Houten/Diegem: Bohn Stafleu Van Loghum; 1999. p. 240-3.

5. Pols J, Griend J van der. Onderwijs rond chronisch zieken in de medische curricula van Nederland. Tijdschrift voor Medisch Onderwijs 2001;20(2): 46-53.

6. Corte E de, Geerligs CT, Lagerweij NAJ, Peters JJ, Vandenberghe R. Beknopte didaxologie. Groningen: Wolters-Noordhoff; 1981.

7. Metz JCM, Pels Rijcken-Van Erp Taalman Kip EH, Brand-Valkenburg BWM van den. Raamplan 1994. Eindtermen van de artsopleiding. Nijmegen: Universitair Publikatiebureau Katholieke Universiteit; 1994.
8. Besluit opleidingseisen arts. Staatsblad. 19-71997;379.

9. Holdrinet RSG, Oeseburg B, Bulte JA, Leunissen RRM, redactie. Kerndoelstellingen tot het doctoraal geneeskunde. Nijmegen: Faculteit der Medische Wetenschappen, Katholieke Universiteit Nijmegen; 1995.

10. Chronisch zieken, uw zorg? Onderwijsarrangement over de begeleiding door de huisarts van mensen met een chronische ziekte. NHG/LHVDeskundigheidsbevorderingspakket 53. Utrecht: Nederlands Huisartsen Genootschap; 1997.

11. Onderwijscommissie Nederlandse Vereniging voor Geriatrie. Eindtermen voor het onderwijs in de geriatrie en gerontologie voor de artsopleiding. Arnhem: Nederlandse Vereniging voor Geriatrie; 1992.

12. Robbins AS, Beck JC. Guidelines for graduate medical education in geriatrics. J Med Educ 1982;57(10 Pt 1):762-8.

13. Walley T, Webb DJ. Developing a core curriculum in clinical pharmacology and therapeutics: a Delphi study [see comments]. Br J Clin Pharmacol 1997;44(2):167-70.

14. Venekamp R, Bootsma-de Langen AM, Aukes LC, Koppelman GH, Kreeftenberg HG, Pols J, et al. Een consensusprocedure voor de ontwikkeling van standaarden voor vaardigheidsonderwijs. In: Pols J, Cate ThJ ten, Houtkoop E, Pollemans MC, Smal JA, redactie. Houten/Zaventem: Bohn Stafleu Van Loghum; 1995. p. 403-6.

15. Nederlandse Vereniging voor Reumatologie. Reumatologie eindtermen voor de artsopleiding. Utrecht: Nederlandse Vereniging voor Reumatologie; 1999.

De auteurs:

J. Pols is als arts werkzaam bij de Afdeling Onderwijsontwikkeling en Kwaliteitszorg van het Onderwijsinstituut van de Faculteit der Medische Wetenschappen en bij de Stafgroep Organisatie en Ontwikkeling van het Academisch Ziekenhuis Groningen. Hij was projectleider van het project 'Onderwijs rond chronisch zieken in C2000'.

J. van der Griend was ten tijde van het onderzoek werkzaam bij de Faculteit der Medische Wetenschappen in Groningen als projectmedewerker bij het project 'Onderwijs rond chronisch zieken in C2000'.

\section{Correspondentieadres:}

J. Pols, Faculteit der Medische Wetenschappen, Afdeling Onderwijsontwikkeling en Kwaliteitszorg, A. Deusinglaan 1, geb 3216, kamer 113, 9713 AV Groningen, tel: 050-3637629,fax:050-3633865,e-mail: j.pols@ med.rug.nl 


\section{Summary}

Introduction: In cases of chronic illness both patients and doctors are faced with somatic, psychological and social consequences. However, in the undergraduate medical curricula in the Netherlands there is little systematic attention paid to the latter two types of consequences. An analysis of the common objectives of medical education in the Netherlands (Blueprint 1994) reveals the same deficiencies. This article reports on a process by which consensus was sought regarding these deficiencies and objectives to be added to Blueprint 1994.

Method: In Groningen we formulated supplementary objectives after consultations with doctors, patients and other experts in the field of chronic illness. In a Delphi-procedure involving thirty participants we asked them to indicate whether they judged the proposed additions to be obligatory, desirable, not really necessary or not necessary, for medical students in Groningen. Agreement among two thirds of the participants was regarded as consensus.

Results: The procedure yielded 123 objectives to be added to Blueprint 1994.

Discussion: The results confirm the presence of deficiencies. The additional objectives are important for the development and evaluation of medical curricula, both in Groningen and at other Dutch medical schools, and can contribute to the revision of Blueprint 1994. (Pols J, Griend J van der. Gaps in Blueprint 1994: supplementary objectives concerning chronic illness. Dutch Journal of Medical Education 2001;20(3): 91-99.) 


\section{Bijlage 1.}

\section{Consensusprocedures: algemene informatie}

Procedures om consensus te ontwikkelen, kunnen worden gebruikt onder omstandigheden waarin 'de' waarheid in het midden ligt (of niet bestaat) en er toch een breed draagvlak wordt gezocht voor een richtinggevend standpunt. ${ }^{2}$ Bekende voorbeelden van de uitkomst van consensusprocedures zijn de standaarden van het Nederlands Huisarts Genootschap en de consensusteksten van het Kwaliteitsinstituut voor de gezondheidszorg $\mathrm{CBO}$. In beide gevallen wordt tijdens de consensusprocedure vastgesteld tot welke grens er aan de wetenschappelijke literatuur een duidelijke richtlijn voor goed medisch handelen ontleend kan worden. Daar waar uitkomsten van wetenschappelijk onderzoek ontbreken (of tegenstrijdig zijn), voorzien de procedures in het raadplegen van een panel van experts, die tot een gezamenlijk standpunt komen. In het eerste traject is vooral sprake van weging van statistisch feitenmateriaal, in het tweede zijn de wegingen veel meer van kwalitatieve aard. Beide trajecten bestaan uit meerdere rondes en het is kenmerkend voor consensusprocedures dat de uitkomsten van de ene beoordelingsronde het ingangsmateriaal vormen voor een volgende.

Om consensus te bereiken zijn verschillende types procedures ontwikkeld. ${ }^{2}$ Een belangrijk onderscheid daarbij is dat tussen schriftelijke procedures en die waarbij de deelnemers met elkaar aan tafel zitten. Een voorbeeld van dat laatste is het expertpanel, waarbij 9-12 deskundigen op een specifiek gebied worden uitgenodigd om tijdens twee of meer bijeenkomsten volgens een vaststaande procedure een gezamenlijk beleid te formuleren rond een probleem, bijvoor- beeld een groep chirurgen die richtlijnen opstelt over de indicaties voor laparoscopisch herstel van liesbreuken.

Voordelen van schriftelijke methodes zijn de mogelijkheid om een grote groep deelnemers te consulteren, de waarborg voor gelijkwaardige inbreng van alle deelnemers (in tegenstelling tot vergaderingen waarin meestal een of meerdere dominante 'smaakmakers' aanwezig zijn) en het feit dat de (drukbezette) deelnemers hun deelname kunnen realiseren op een moment dat het hen schikt. De bekendste schriftelijke consensusprocedure is de Delphi-methode. Daarbij wordt de deelnemende experts in enkele rondes een vragenlijst voorgelegd waarin zij bij de opgenomen items op een Likertschaal aan kunnen geven in welke mate zij het met het item (on)eens zijn. Veelal wordt daarbij gebruik gemaakt van een schaalverdeling die loopt van 'helemaal mee eens' tot 'helemaal niet mee eens'. In elke volgende ronde krijgen de deelnemers een overzicht van de resultaten uit de vorige ronde en hebben zij de mogelijkheid om hun eigen oordeel in het licht daarvan te herzien. De procedure wordt herhaald, totdat de gewenste mate van consensus is bereikt.

\section{Literatuur}

1. Everdingen JJE van. Consensusontwikkeling in de geneeskunde. [proefschrift] Bohn, Scheltema \& Holkema, 1988.

2. Jones J, Hunter D. Consensus methods for medical and health services research. BMJ 1995; 311(7001): 376-80. 